\title{
APPLYING PARTIAL ORDER AND SWOT ANALYSIS IN WATER AND LAND USE PLANNING TO PRIORITIZE THE ADAPTATION STRATEGIES UNDER CHANGING CLIMATE
}

\author{
Solaymani Hamidreza \\ Member of High council in Forest, Range and Watershed Management \\ Organization - FRW (IRAN) (http://Www. frw.org.ir) \\ hrsolaymani[at]yahoo.com \& solaymani.hamidreza[at]frw.org.ir
}

\begin{abstract}
The present study is focused on the adaptation formulation in water sector under the IWRM (Integrated Water Resources Management) approach. IWRM approach looks for a framework, which addresses policy objectives and the physical state in the water and land-use planning. This approach looks for the agreements between different water beneficiaries i.e., agriculture, natural system and industry and the exsiting water resources. The main objective of this approach can be conducted to explore adaptation actions to address implications on account of climate change impacts under various land-uses.

There are broad operations in IWRM approach that have been characterized for formulation of adaptation options. The priority of the differnt operations were achieved based on questionnaire, SWOT (Strengths, Weaknesses, Opportunities and Threats), and Partial Order Analysis (POA) at this research work. Four possible operations have been selected: management operations for agricultural, management operations for natural system purpose, changing crop pattern, and changing the land-use. The ranked adaptation operations under the changing climate were exposed at the end.
\end{abstract}

Keywords: IWRM, Adaptation, Water and Land Use, SWOT, POA

\section{INTRODUCTION}

In an overall view, adaptation approaches are divided into autonomous and planned approaches [1]. Autonomous approach indicates the improvement and/or amplifications of existing risk management and facilitating particular adaptation. These are mainly available by individual stakeholders, rural communities, and nongovernmental organizations that are working without major intervention of regional/national government. Planned approach includes the changes in policies, developing new infrastructures and policies that support, facilitate, improve and maximize the benefits through management and land-use changes [2]. It is mainly implemented by decision makers and planners. However, the changes on the mean and frequency of the climate variables will shift the risk zone that is not covered through present autonomous and planned adaptation (Figure 1). It means that the risk zone will increase considerably which shall in turn need to revise both autonomous and planned adaptation [3]. 
The research work is focused on formulation of the adaptation strategy to water and land-use planning based on SWOT and POA analysis. In watershed based studies, a regional hydrological cycle is bounded more by watershed than by an administrative boundary. Therefore, it is clear that the downstream water availability completely depend on upstream water-related activities. Integrated watershed based adaptation to climate change on water resources has been reported by several studies $[4,5,6,7,8,9,10,11,12,13,14$ and 15]. Thus, the main objective is to formulate planned adaptation measures to climate change in the watersheds in light of the water resources challenges and prioritization of the same. The strategy shall focus on water resources conservation as well as agriculture and water management. The research work has followed the strategy of integrated hydrological model with the framework that has been applied for some of the climate change projects such as ADAPT project (http://www.geo.vu.nl/users/ivmadapt) developed by $[10,11,12$ and 13].

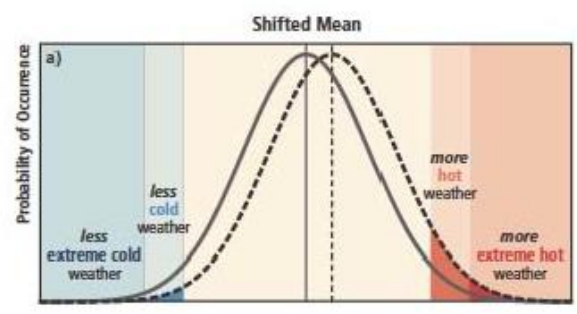

Changed Symmetry

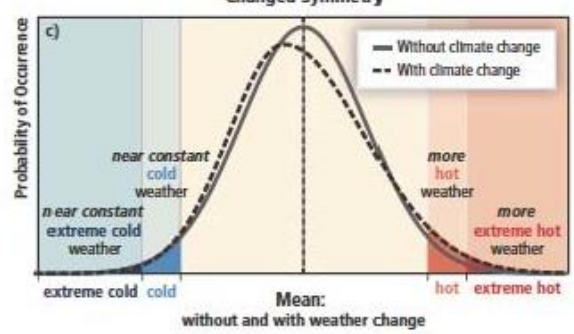

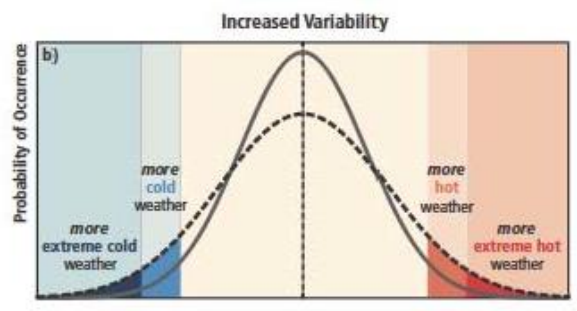

Figure 1 Schematic showing the effect on extreme temperatures when the mean temperature increases, for a normal temperature distribution (Adopted: IPCC 2007: WG1- AR4)

\section{ADAPTATION STRATEGY IN WATER SECTOR}

The adaptation strategy includes various plans of actions to be implemented through policies and measures over the future climate change. The objectives of adaptation strategy can be very specific and significantly broad. Adaptation strategy in water resources to address a number of trends by climate change is usually no different from the present day coping the interventions [16]. IPCC [2] has published a technical report on water and climate change. It outlines three approaches to address climate change adaptation strategy in water sector:

- Scenario based planning approach that is defined to improve the possible future storylines to facilitate the decision making under uncertainty. It was developed based on a set of assumptions of the key relationships and driving forces of climate change. It includes the predictable and unpredictable characteristics of climate changes, environment and socioeconomic factors. It is being practiced in UK [17] and Australia [18]. 
- Adaptive management approach, which prescribes enhanced use of water management measures robust enough to cope uncertainty, is being deployed to minimize the water demand as well as offer a system to cope with climate change has been reported by [19]. It is also being applied by Ministry of Water Resources in China [20].

- Integrated Water Resources Management (IWRM) approach is responsible for engaging various stakeholders; modifying planning process; coordinating land and water resources management; and conserving and rehabilitating natural resources. IWRM can facilitate synergetic decisionmaking and help considering competing demands between water uses. It can facilitate negotiations between stakeholders to achieve cooperatively satisfactory problem solving that covers broad divers factors. Moench et al. [21] reported that a complete IWRM is not always needed. The sufficient scale of integration will depend on the extent to which it facilitates effective action in response to specific need. This approach is implemented in four basins in India and one in Nepal.

Adaptation strategy in water sector is not just regarding climate change [22]. It can be used to take account of the anthropogenic stressors e.g. land-use change competition between water uses, population growth, transboundary water allocation, environmental concern and so on. The term 'no- regret strategy is therefore often used, since implementing an adaptation strategy may solve a problem due to climate change. If it cannot solve the negative climate change impacts, it may solve other even bigger problems e.g. development problems [6].

\section{IWRM: A GOAL-BASED PERFORMANCE APPROACH}

IWRM approach looks for a framework, which addresses policy objectives (e.g. formulated in general water management plans) and the physical state in the watershed. It means, IWRM develops an integrated approach to water resource management through multi-pathways to watershed resilience. This approach recognises and then builds agreements between different water beneficiaries including agriculture, natural system and industry. It encourages all the stakeholders impacted upon by climate change to find and improve "win-win" solutions which have also been highlighted in the IWRM as 'no-regret approach' earlier.

Therefore, the key principle on IWRM included:

- Water should be treated as an economic, social and environmental good;

- Water policies should focus on both the management of water (demand) and the provision of water (supply);

- Government regulatory frameworks are critical in fostering the sustainable development of water resources;

- Water resources should be managed at the lowest appropriate level (i.e., in communities and villages as opposed to in capitals); and

- Women should be recognized for and supported in the central role they play in the provision, management and safeguarding of water [23]

This approach includes both "hard" physical and "soft" institutional activities. Without any doubt, the coupling of both hard and soft activities gives the best 
chance of coping and adapting to negative impacts of climate change on water sector successfully. Application of the soft tools is prepared and before completing the hard operations objectives and guarantying the hard activities investments. The art of IWRM involved in choosing, adapting and using the right mix of these operations for a given situation. IWRM is a multidisciplinary approach that can be implemented and put into practice depending on the adaptive capacity of countries' institutions. Agreeing on milestones and time-frames for executing the approach is critical for success. Implementation may take place on a step-by-step basis, in terms of spatial and temporal reforms. Scope, timing, and content of measures can be adjusted according to experience. This offers room for change, improvement and process adjustment, provided that the proper bases for sound decision making have been established. In developing an approach and framework for change, it is important to recognize that the process of change is unlikely to be rapid.

Regarding the objectives of this study and hydrological modelling performances, the choices of hard physical scenarios have been selected. Enhancing the water efficiency is the simplest answer to water scarcity in IWRM approach. It can be improved for both agriculture, and water management as well as in nature conservation by implementing the management practices, changing cropping pattern, using recycle water, constructing the reservoirs and so on. The legitimate step to lead the adaptation strategy is to formulate the adaptation based on IWRM approach.

\section{FORMULATION OF ADAPTATION STRATEGY}

Once the broad outcomes of the IWRM approach are characterized, it is possible to formulate institutional and physical operations to achieve these outcomes. An important step in the process of formulating options is to integrate the adaptation polices and measures between different sectors and with existing policies and operations. This step builds on the synergies identified early on in scenario design by ensuring that the overlaps and intersections between adaptations and existing policies and measures are co-ordinated to the benefit of both. With integration, potential conflicts between adaptations in different sectors, and between proposed adaptations and existing policies and measures, can be avoided or limited. It is well known, for example, that developing an adaptation scenario in the agriculture sector without considering the water sector is not really feasible due to the close relationship between the two. The same can be said for natural resources and water.

In this study, the physical scenarios are been considered, followed with the formulation and implementation process. Even purely physical adaptations (e.g., dam construction, changes in agricultural practices, establishment of rain water harvesting, etc.) will need integration. Panagopoulos et al. [24] have been used an integrated modelling system based on SWAT (Soil and Water Assessment Tool) to estimate the in-stream water and non-point sources pollution yields in response to a wide array of alternative cropping and management strategies under projected climatic conditions of the corn belt region in the Midwestern US. They realized the 
rate of erosion and nutrient loading to surface water bodies were reduced compare to the baseline condition. They also understood the corn and soybean yields were highly influenced from the agricultural management scenarios. Another relevant study has been done with Woznicki et al. [25] for the Tuttle Creek Lake watershed in Kansas and Nebraska. They studied the impact of some agricultural BMPs; e.g. Terraces, contour farming etc, on Water yield, surface runoff, base-flow, sediment load, nitrogen load, and phosphorus load by using SWAT and projected climatic conditions. They were resulted terraces, contour farming, and native grass were determined to be the most effective in pollution load reduction and percent efficiency at the field and watershed scales in future scenarios. Porous gully plugs and filter strips showed no significant changes in pollution load or percent reduction. Grazing management, no-tillage, conservation tillage, and grazing management percent and load reduction in future scenarios varied at the field and watershed scales. Their study demonstrated that BMP performance in terms of sediment, nitrogen, and phosphorus reduction significantly changes in future climate scenarios at the field scale, while performance generally does not change significantly at the watershed scale.

Of course, formulating an adaptation scenario covers the common issues of interests and damages, and the problem of how to attribute those interests and damages to various sectors. In order to formulate the adaptation scenario, first the various possible adaptation options should be known then the application possibilities can be validated.

\subsection{ADAPTATION ACTIVITIES}

Adaptation activities take place in the wide range of physical options in IWRM approach. Six main scenarios have been reported by [26]:

$\checkmark$ Diversification of Water Supply

$\checkmark$ Groundwater Recharge

$\checkmark$ Preparation for Extreme Weather Events $\checkmark$ Resilience to Water Quality Degradation

$\checkmark$ Stormwater Control and Capture

$\checkmark$ Water Conservation.

The suggested scenarios include various practices/technologies and management operations. They had also reported, in addition to the above scenarios, many crucial contributing practices to adaptation efforts. It is required to prioritize the above eight operations, with respect to functionalities/capabilities for hydrological character, socio-economical, and ecological/technological limitations. In order to achieve this objective, it is needed first to know the strength, weakness, opportunities, and threats of each scenario; then, their ordering and prioritizing by using order analysis.

\subsection{ACTIVITIES PRIORITIZATION}

IWRM approach involves operations and actions anticipated at enhancing the water conservation and the efficiency in its use, while decreasing conflicts among competing uses, both in quantity and quality. However, usually the prioritization 
of the adaptation activities conceived is missing. Therefore, it is intended to prepare a possible methodology to prioritize adaptation activities agreed on the IWRM approach. The later part is achieved using SWOT, and Partial Order Analysis (POA).

\subsubsection{SWOT ANALYSIS}

SWOT (Strengths, Weaknesses, Opportunities and Threats) analysis is a useful tool for the integrated and sustainable planning development and decision making and has widely been applied to environmental planning and water resource management [27 28 and 29]. Strengths and weaknesses are the factors with internal issues, while opportunities and threats are the factors with external issues. Danca [30] has reported that it is necessary to minimize both weaknesses and threats, and the weaknesses should be converted into strengths in the SWOT application. Furthermore, threats should be converted into opportunities. Likewise, strengths and opportunities should be matched to optimize the water resources in a basin. Table (2) shows the basic concept of SWOT analysis. It also highlights definitions and concepts of SWOT.

Evaluation of the aforementioned elements of SWOT analysis may give the qualitative evaluation to researchers and/or decision makers. However a quantitative analysis is required for which the Partial Order Analysis (POA) can been used. Since, the SWOT properties have two opposite orientation; therefore, it has been decided to define the rating scores to be executed in POA. The beneficial aspects have taken the positive scores and the harmful properties the negative scores (Table 3).

Each cell of SWOT properties consists of some ${ }^{1}$ main characteristics, which indicated the function of each activities; e.g. if the A1 (activity number 1) has be taken three tick marks concerning strengths property, and the beneficial score is ' 3 '. It means the performance rating is "very good" for $A 1$ in strengths property. Then, the scores for all the selected scenarios are calculated, and summation of the scores is shown the final performance for each scenario.

\footnotetext{
${ }^{1}$ It has no limitation on the number of characteristics in SWOT properties. It is assumed to have equal number of characteristics for each property (strength, opportunity, weakness, and threats) due to keep the balance between positive and negative rating scores.
} 
Table 2 Schematic showing of the SWOT analysis

\begin{tabular}{|c|c|c|}
\hline & Beneficial & Harmful \\
\hline 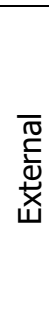 & $\begin{array}{l}\text { Strengths } \\
\text { Inherent abilities of the selected } \\
\text { activities in adaptation based on; i) } \\
\text { socio-economic conditions, ii) } \\
\text { Environment condition, and iii) } \\
\text { Technical conditions in selected basin. }\end{array}$ & $\begin{array}{l}\text { Weaknesses } \\
\text { Deficiency of the selected activities in } \\
\text { adaptation regarding; i) No response to } \\
\text { negative impacts of climate change, ii) } \\
\text { Insufficient level of awareness and } \\
\text { knowledge, and iii)No response to peak } \\
\text { demands for water-use during summer } \\
\text { when water is least available }\end{array}$ \\
\hline 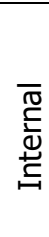 & $\begin{array}{c}\text { Opportunities } \\
\text { Capabilities of the selected activities in } \\
\text { adaptation concerning; i) Application } \\
\text { in hydrologic model, ii) Execution in } \\
\text { study area, and iii) Interest of funding } \\
\text { sources. }\end{array}$ & $\begin{array}{c}\text { Threats } \\
\text { Weakness/Hazards of the selected } \\
\text { activities in adaptation; i)No-response to } \\
\text { floods, ii)No-response to drought, and iii) } \\
\text { Threats for investments if not properly } \\
\text { planned }\end{array}$ \\
\hline
\end{tabular}

Table 3 General performance rating scores to adaptation scenarios regarding expert judgments on SWOT properties

\begin{tabular}{ccc}
\hline Performance Rating & Beneficial Score & Harmful Score \\
\hline Very good/sensitive & 3 & -3 \\
Good/Sensitive & 2 & -2 \\
Normal/Generic & 1 & -1 \\
Non performance & 0 & 0 \\
\hline
\end{tabular}

The next step was to calculate scores for all e.g. eight scenarios (A1, A2 ..., A8) based on SWOT properties. With these scores, specific adaptation scenario's performance can be obtained based on general performance ratings (Table 4).

Table 4 Performance of the outputs in adaptation scenarios

\begin{tabular}{cccccc}
\hline Scenario & Strength & Opportunity & Weakness & Threat & Total \\
\hline A1 & 3 & 3 & -1 & -1 & 4 \\
A2 & 3 & 3 & -1 & -1 & 4 \\
A3 & 1 & 2 & -1 & -1 & 1 \\
A4 & 1 & 1 & -1 & -2 & -1 \\
A5 & 2 & 2 & -1 & -2 & 1 \\
A6 & 1 & 1 & -1 & -2 & -1 \\
A7 & 1 & 2 & -1 & -2 & 0 \\
A8 & 2 & 2 & -1 & -1 & 2 \\
\hline
\end{tabular}

\subsubsection{PARTIAL ORDER ANALYSIS (POA)}

In POA, objects characterized by multiple indicators, can be compared and ordered. Partial order as the theory of order is applied to the set of objects and it delivers insights which results in appropriate ranking of objects [31]. A partial order is a binary " $\leq$ " over a set $P$ which is reflexive, anti-symmetric, and 
transitive, i.e., for all $a, b$, and $c$ in $P$, we have that:

- $a \leq a$ (reflexivity);

- If $a \leq b$ and $b \leq a$ then $a=b$ (anti-symmetry);

- If $\mathrm{a} \leq \mathrm{b}$ and $\mathrm{b} \leq \mathrm{c}$ then $\mathrm{a} \leq \mathrm{c}$ (transitivity).

Regarding the total scores in table (3), the Hasse ${ }^{2}$ diagram was chosen in order to visualize the level ranking of the adaptation activities (Figure 2). The adaptation activities are located vertically in the drawing plan in order to get them organized in 'levels'. For example, activity 1 and 2 'A1\&A2' forms the first level, activity number 8 ' $\mathrm{A} 8$ ' the second, activity 5 'A5' the third, both activities 3 and 5 'A3\&A7' the fourth, and finally activities 4 and 6 ' $A 4 \& A 6^{\prime}$ the fifth level. The highest possible one is selected if an object could be located in several vertical positions.

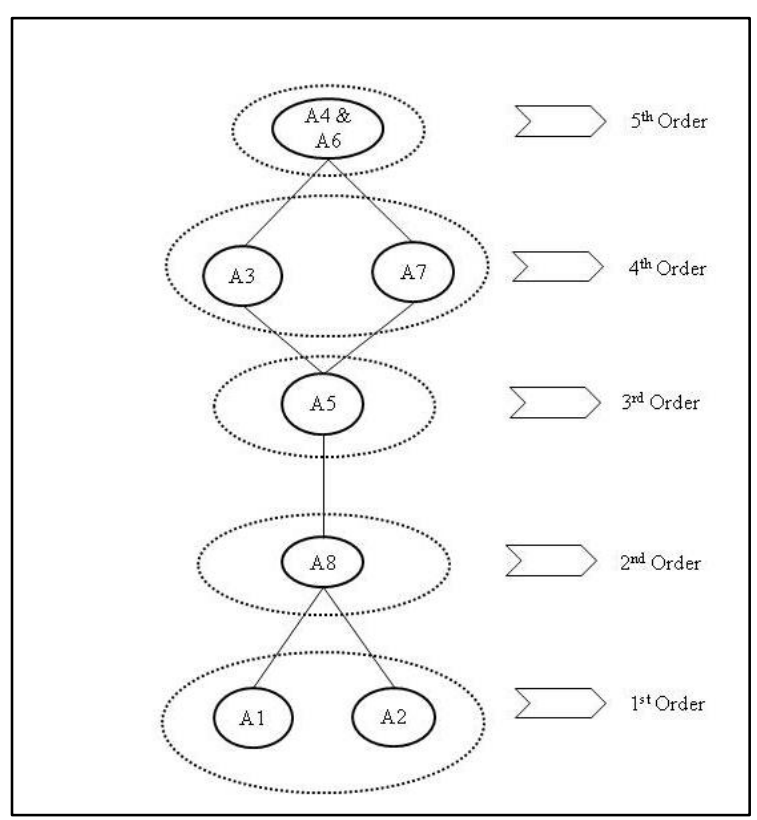

Figure 2 Hasse diagram for adaptation scenarios based on data in Table 4

\footnotetext{
${ }^{2}$ Consider $\mathrm{x}$ and $\mathrm{y}$, and assume that $x \leq y$. Then it draws $x$ in a vertical plane below $y$ and connects both with a straight line. This repeated for every order pair, i.e., for all pairs of two objects for which $\leq$ relation holds. The resulting diagram is denoted as Hasse diagram (sometimes partial order set diagram, order diagram, line diagram, or simply the diagram) after the German mathematician Hasse, who made this kind of visualization popular [31]
} 


\section{CONCLUSION}

Results of the studies on adaptation in various countries [32, 33 and 34] show that to be effective in designing responses to climate change, the prioritization analysis should be applied in order to get the all stakeholders needs and knowledge in providing locally-relevant responses that are the combination of development choices in adaptation options. Furthermore, the process should help in bilateral transfer of knowledge and experiences for stakeholders about the adaptation to changing the climate and their implications at the local/regional and national levels.

The proposed tool for prioritization of adaptation measures fulfills the general objective proposed for this research work. The existing implementation of POA and SWOT analysis prioritize the adaptation activities and can result in enhancing the water and land-use planning under various climate change scenarios. Even though the results of this article reflect the author judgment and then it is considered to be empirically relevant.

\section{REFERENCES}

[1] IPCC (2007) "Contribution of Working Groups I, II and III to the Fourth Assessment Report of the Intergovernmental Panel on Climate Change", Core Writing Team, Pachauri, R.K. and Reisinger, A. (Eds.) IPCC, Geneva, Switzerland. 104pp.

[2] Bates, B.C., Z.W. Kundzewicz, S. Wu and J.P. Palutikof, Eds. (2008) "Climate Change and Water", Technical Paper of the IPCC, IPCC Secretariat, Geneva, 210 pp.

[3] Kabat, P., Van Schaik, H. (2003) "Climate changes the water rules: how water managers can cope with today's climate variability and tomorrow's climate change" Dialogue on Water and Climate, Netherlands. Available from: www.waterandclimate.org.

[4] Aerts J. and P. Droogers, (2009) "Adapting to climate change in the water sector", pp.87-108. In: Climate Change Adaptation in the Water Sector. Ludwig F., KabatP., van Schaik H. and van der Valk M. (Eds). Earthscan: London, UK.

[5] Aerts, J. and P. Droogers, (2005) "Adaptation for Regional Water Management", In: Aerts, J. and P. Droogers, Climate Change in Contrasting River Basins, CABI Publishing.

[6] Aerts, J., Droogers, P. (Eds.), (2004) "Climate Change in Contrasting River Basins: Adaptation Strategies for Water, Food, and Environment", CABI Books, London, p. 288. 
[7] Aerts, J., Lasage, R., Droogers, P. (2003) "ADAPT, a framework for evaluating adaptation strategies". Report number R-03/08, Institute for Environmental Studies (IVM), Vrije Universiteit Amsterdam.

[8] Aerts, J. and P. Droogers (2005) " Adaptation for Regional Water Management", In: Aerts, J. and P. Droogers, Climate Change in Contrasting River Basins, CABI Publishing.

[9] Droogers, P., Immerzeel, W. W., Terink, W., Hoogeveen, J., Bierkens, M. F. P., van Beek, L. P. H., and Debele, B. (2012) "Water resources trends in Middle East and North Africa towards 2050", Hydrol. Earth Syst. Sci., 16, 3101-3114, doi: 10.5194/hess-16-3101

[10] Droogers, P. (2009) "Climate Change and Hydropower, Impact and Adaptation Costs: Case Study Kenya", Future Water Report, 85.

[11] Droogers, P. and Aerts, J. (2005) "Adaptation strategies to climate change and climate variability: a comparative study between seven contrasting river basins", Phys. Chem. Earth, 30, 339-346.

[12] Droogers, P. (2004) "Adaptation to climate to enhance food security and preserve environmental quality: example for southern Sri Lanka", Journal of Agriculture Water Management, 66: 15-33.

[13] Dessai, S., Hulme, M., Lempert, R., and Pielke, R. (2009) "Do We Need Better Predictions to Adapt to a Changing Climate?" EOS, 90,111-112, 2009.

[14] Dessai, S., X. Lu and J.S. Risbey (2005) "On the role of climate scenarios for adaptation planning", Global Environment Change, 15, 87-97.

[15] Dessai, S., Hulme, M. (2004) Does climate adaptation policy need probabilities? Climate Policy 4, 107-128.

[16] Gosain, A. K., Sand hya Rao, Basuray, D. (2006) "Climate change impact assessment on hydrology of Indian river basin", Current science, Vol. 90, No 3.

[17] Arnell, N.W. \& Delaney, E.K., (2006) "Adapting to climate change: public water supply in England and Wales", Climatic Change 78, 227-255.

[18] Dessai, S., X. Lu and J.S. Risbey (2005) "On the role of climate scenarios for adaptation planning", Global Environment Change, 15, 87-97.

[19] Beuhler, M. (2003)"Potential Impacts of Global Warming on Water Resources in Southern California", Water Science Technology, 47(7-8), 165-168.

[20] Xia, J., Bing Qiu and Yuanyuan Li (2012) "Water resources vulnerability and adaptive management in the Huang, Huai and Hai river basins of China", Water International, Vol. 37, No. 5, 523-536. 
[21] Moench, M., A. Dixit, S. Janakarajan, M.S. Rathore and S. Mudrakartha, (2003) "The Fluid Mosaic: Water Governance in the Context of Variability, Uncertainty and Change - A Synthesis Paper", Nepal Water Conservation Foundation, Kathmandu, 71 pp.

[22] Burton, I., Smith, J., and Lenhart, S. (1998) "Assessment In: Feenstra, J.F., Burton, I., Smith, J, B., and Tol, R, S, J., (eds) UNEP Handbook on Methods for Climate Change Impact Assessment and Adaptation Strategies", Institute for Environmental Studies, Vrji Universiteite Amsterdam.

[23] Solanes, M., F. Gonzales, (1999) "The Dublin Principles for Water as Reflected in a Comparative Assessment of Institutional and Legal Arrangements for Integrated Water Resources Management", TEC Background Paper No. 3, Global Water Partnership, Stockholm, Sweden.

[24] Panagopoulos, Y, P. W. Gassman, R. W. Arritt, D. E. Herzmann, T.D. Campbell, A. Valcu, et al (2015) "Impact of Climate Change on Hydrology, Water Quality ad Crop Productivity in the Ohio - Tennessee River Basin", Int. J. Agric \& Biol. Eng, 8(3): 36-53.

[25] Woznicki, S.A., A.P. Nejadhashemi, C.M. Smith (2013) "Assessing Best Management Practice Implementation Strategies under Climate Change Scenarios" Transaction of the ASABE, 54(1): 171-190, doi: 10.13031/2013.36272.

[26] Elliot, M., Armstrong, A., Lobuglio, J. and Bartram, J. (2011) "Technologies for Climate Change Adaptation in Water Sector", T. De Lopez (Ed.), Roskilde: UNEP Risoe Centre

[27] AHRD (Academy of Human Resource Development), (2001) "Performing the SWOT Analysis", http://www.academyofhrd.org/clswot.htm.

[28] Baser, O. (2001) "SWOT Analysis: A Practical Guide for Young Managers", http://www.baserler.com.tr/onur/isletme/management\%20skills-swot.htm.

[29] ELARD (Earth Linked and Advanced Resource Developments) (2004) "Optimization for Sustainable Water Resources: Lebanon Case Study-The Lower Litani River Basin",

http://www.google.com/search?q=cache:Shr4SIfzwYEJ:www.ess.co.at/OPTIMA/FT P/LB.ppt+SWOT+analysis.

[30] Danca, A. (2000) "An explanation of the SWOT analysis process",http://www.stfrancis.edu/ba/ghkickul/stuwebs/btopics/works/swot.htm.

[31] Bruggmann R. and Patil G. P. (2011) "Ranking and Prioritization for Multiindicator Systems, Introduction to Partial Order Applications, Springer Pub. 
[32] Ahiable, G. and K. A. Salam, (2009) "Report of Zonal Workshops, Prepared for the World Bank Participatory Development Associates Ltd.", Kumasi, pp. 26.

[33] Bizikova, L., J. Robinson, and S. Cohen, (2007) "Linking climate change and sustainable development at the local level", Climate Policy, Special Issue, 7(4): 271-277.

[34] Bizikova, L., S. Cohen, S. Burch and J. Robinson, (2009) "Exploring linkages between climate change and sustainable development to facilitate changes on the Ground", In: O'Brien K. and A. L. St. Clair (Eds.), Shifting the Discourse: Climate Change as an Issue of Human Security, Cambridge University Press.

Article distributed under a Creative Commons AttributionNonCommercial-NoDerivatives 4.0 International License (CC BY-NC-ND).

Received: May 15, 2018

Accepted: June 8, 2018. 